\title{
Down-regulated expression of transient receptor potential ankyrin 1 in lichen simplex chronicus
}

\author{
Yang Qiu, Nan Tang, Wen Zhang, Jian-Xia Xiong, Li Hu, Tao Cai \\ Department of Dermatology, The First Affiliated Hospital of Chongqing Medical University, Chongqing, China \\ Contributions: (I) Conception and design: T Cai; (II) Administrative support: T Cai; (III) Provision of study materials or patients: Y Qiu; (IV) \\ Collection and assembly of data: Y Qiu, N Tang, W Zhang, JX Xiong, L Hu; (V) Data analysis and interpretation: Y Qiu, N Tang, W Zhang, JX \\ Xiong, L Hu; (VI) Manuscript writing: All authors; (VII) Final approval of manuscript: All authors. \\ Correspondence to: Tao Cai. Department of Dermatology, The First Affiliated Hospital of Chongqing Medical University, No. 1 Youyi Road, \\ Yuanjiagang, Yuzhong District, Chongqing, China. Email: caidaodao@hotmail.com.
}

\begin{abstract}
Backgroundk Lichen simplex chronicus (LSC) is an acquired chronic dermatosis that is often accompanied by severe paroxysmal pruritus, and its pathogenesis to date is still unclear. Transient receptor potential channel A1 (TRPA1) is a non-selective cation channel. TRPA1 is widely expressed in skin, sensory neurons, and various other tissues, along with various biological functions and activation mechanisms. This study aimed to explore the changes in TRPA1 expression in human LSC and provide evidence for further research on the role of TRPA1 in chronic pruritus.

Methods: A total of 21 skin lesion specimens from LSC patients with skin pruritus lasting more than 6 weeks, and 28 normal skin tissue specimens through the skin biopsy from June 2018 to February 2019 were collected. The expression of TRPA1 in these skin tissues was evaluated through western blotting, quantitative reverse transcription PCR (qRT-PCR), and immunohistochemical analysis. The changes of inflammatory mediators, including interleukin (IL)-6, IL-13, endothelin-1 (ET-1), and thymic stromal lymphopoietin (TSLP), as well as substance P, are also analyzed by qRT-PCR. TRPA1 was detected using immunohistochemistry for all skin layers, the basal layer, and around the blood vessels of the dermis.

Results: The expression of TRPA1 in LSC specimens was significantly decreased as compared with that in the normal specimens $(\mathrm{P}<0.05)$. Also, TRPA1 protein levels were consistently decreased in LSC specimens $(\mathrm{P}<0.05)$. Simultaneously, the mRNA expressions of TRPA1, IL-6, IL-13, ET-1, TSLP, and substance P presented with no significant differences between LSC and normal specimens.
\end{abstract}

Conclusions: TRPA1 expression is proved downregulated in skin lesions of LSC patients with skin pruritus, indicating that TRPA1 serves as a crucial role in the pathogenesis of human LSC.

Keywords: TRPA1; lichen simplex chronicus (LSC); pruritus

Submitted Jul 23, 2020. Accepted for publication Oct 24, 2020.

doi: 10.21037/apm-20-1712

View this article at: http://dx.doi.org/10.21037/apm-20-1712

\section{Introduction}

Itching is an unpleasant cutaneous sensation originating from layers of the skin or the mucosa, which provokes the desire to scratch the affected area. Many mediators, receptors, and cells, and specific neural circuits responsible for scratching behavior, have been found. Chronic pruritus, characterized by daily itching lasting more than 6 weeks, is the most common symptom in dermatological conditions and some systemic disorders. The underlying cause of lichen simplex chronicus (LSC) is still unclear, and its inflammatory skin condition presents with chronic and often severe pruritus.

Transient receptor potential channel A1 (TRPA1) is a nonselective cation channel that belongs to the TRP superfamily. It decreases the electrochemical gradient of cations $\mathrm{Ca}^{2+}$ and 
$\mathrm{Na}^{+}$by regulating their transmembrane transport, thereby causing cell membrane depolarization in response to the increased intracellular concentrations of $\mathrm{Ca}^{2+}$ and $\mathrm{Na}^{+}$(1). TRPA1 is widely expressed in skin, sensory neurons, and various other tissues, along with various biological functions and activation mechanisms. TRPA1 shows a response to cold at a temperature of lower than $17^{\circ} \mathrm{C}(2)$, and it can be activated by pungent natural compounds, environmental irritants, formalin, and endogenous analgesics as well.

TRPA1-positive neurons are an essential basis of several signaling pathways that promote histamineindependent pruritus. BAM8-22 peptides can stimulate the neurons (3), SLIGRL peptide $(4,5)$, interleukin (IL)31 (6), oxidative stress (7), and chloroquine (8) as reported, and the histamine-independent itching sensation induced by these mediators is accordingly vanished in TRPA1-/mice (9). A significant reduction in itch-induced scratching behavior can be observed in TRPA1-/- mice with chronic pruritus with the treatment of TRPA1 antagonists, and emerging evidence showing TRPA1 acts as a vital role in chronic pruritus $(3,10-12)$. The TRPA1 channel is currently considered the critical ligand-gated channel in the peripheral itch signaling pathway, and it serves as the downstream molecule of most itch receptors for its excitement on primary sensory neurons after activation.

LSC also known as neurodermatitis circumscripta, is an itchy skin condition causing thickened skin at the areas of skin injured by repeated scratching and rubbing. Its histology resembles palmoplantar skin even at other localizations. Research shows that the serine protease inhibitor of Kazal-type 9 (SPINK9) is expressed in LSC. SPINK9 is a specific inhibitor of the serine protease kallikrein-related peptidase 5 (KLK5), which contributes to the desquamation process of the stratum corneum. Upregulated SPINK9 expression in LSC contributes to the typical clinical finding of hyperkeratosis in this disease (13). But the pathogenesis of LSC to date is still unclear. At present, typical therapeutic methods include medication and physical therapy. Conventional medications, such as a local application of hormonal therapy, have a long treatment course because the "itchscratch" cycle remains and the symptoms recur unless lichenification resolves (14). In this study, cases with LSC as the representative disease featuring chronic pruritus were chosen to clarify the relationships of the expression of TRPA1 with pruritus and inflammation in LSC. We present the following article in accordance with the MDAR reporting checklist (available at http://dx.doi. org/10.21037/apm-20-1712).

\section{Methods}

\section{Subjects}

A total of 21 skin lesion specimens (14 males and 7 females) from LSC patients with skin pruritus lasting more than 6 weeks from June 2018 to February 2019 were collected in the Department of Dermatology of the First Affiliated Hospital of Chongqing Medical University, Chongqing, China. The average age was $43.88 \pm 17.59$ years old. The pruritus sites included trunk ( 2 cases), extremities (16 cases), head/face ( 1 case), and vulva/scrotum ( 2 cases). These skin lesion specimens from LSC patients were taken as LSC group. In the meantime, 28 normal skin tissue specimens (13 males and 15 females) through simple lipomatectomy were collected as a control group. The average age was $48.57 \pm 17.27$ years old. Lipoma sites include trunk (9 cases), extremities (16 cases), head/face (2 cases), and vulva/ scrotum (1 case). The Medical Ethics Committee approved the study of the First Affiliated Hospital of Chongqing Medical University, and informed consent was obtained from all the included subjects. All procedures performed in this study involving human participants were in accordance with the Declaration of Helsinki (as revised in 2013).

\section{Sample collection}

All skin tissues from both groups were excised under local anesthesia and divided into two parts. One part was soaked and fixed in $4 \%$ paraformaldehyde solution for 6 hours, and then was embedded in paraffin for the following immunohistochemical analysis after conventional dehydration. The other part was transported after liquid nitrogen freezing and stored in a refrigerator at $-80^{\circ} \mathrm{C}$ for western blotting and quantitative reverse transcription PCR (qRT-PCR).

\section{Immunobistochemical analysis}

Paraffin-embedded tissue blocks were sectioned at a thickness of $5 \mu \mathrm{m}$ and then were dewaxed and hydrated conventionally. Sections washed with deionized $\mathrm{H}_{2} \mathrm{O}$ were placed into citrate buffer solution $(0.01 \mathrm{~mol} / \mathrm{L}, \mathrm{pH}$ 6.0) and heated in a microwave for antigen retrieval. Then the sections were rinsed three times with phosphatebuffered saline for 5 minutes each time after the buffer naturally cooled down to room temperature. The sections were placed on a flat level surface in wet boxes with a small amount of distilled water, and enough drops of $3 \%$ hydrogen peroxide to cover the surface of the sections for 
inactivating endogenous peroxidase. After shaking off the excess fluid with a brisk motion, the sections were added with a blocking solution and incubated for 10 minutes at room temperature. Then the rabbit anti-human TRPA1 polyclonal antibody (1:200; ACC-037, Alomone Labs, Jerusalem, Israel) was added dropwise to cover the sections, followed by incubation overnight at $4{ }^{\circ} \mathrm{C}$ in a humidified chamber in the dark. On the following day, enough goat anti-rabbit IgG (1:500; Thermo Fisher, America) was added dropwise to cover the sections after rewarming for 40 minutes at room temperature, followed by incubation at room temperature for 30 minutes in a humidified chamber. After incubation, the color development is performed using the peroxidase-diaminobenzidine solution at room temperature. After that, the sections received nuclear counterstaining with hematoxylin, ethanol dehydration in a reverse gradient, and clarification in xylene. Subsequently, the sections with coverslips were sealed using neutral resin, followed by section scanning using KF-PRO-005 Digital Pathological Slide Scanner (Ningbo KONFOONG Bio, China). The total and average optical densities of positive staining were quantitatively calculated using Image-Pro Plus 6.0 analysis software.

\section{Western blot assay}

A small tissue block with a size of about $5-\mathrm{mm}^{3}$ is cut off from the skin tissues preserved at $-80^{\circ} \mathrm{C}$, and $1 \mathrm{~mL}$ of RIPA cell lysis reagent containing phenylmethylsulfonyl fluoride $(10: 1)$ was added for protein extraction. Then the skin tissues were ground into homogenate using an electric homogenizer. Subsequently, the supernatant was collected after centrifugation at 12,000 r/minutes for 15 minutes. The protein concentration was determined as per the instructions of the Bicinchoninic Acid Protein Assay Kit (Beyotime Biotech, Shanghai, China). The absorbance value at $562 \mathrm{~nm}$ was determined. The protein concentration of a sample was calculated according to the standard curve and the protein volume. The remaining supernatant was mixed with a $5 \times$ protein loading buffer at the ratio of $1: 4$ in volume, and then the mixture was heated at $100{ }^{\circ} \mathrm{C}$ for 10 minutes. The proteins in a sample were separated using sodium dodecyl sulfate-polyacrylamide gel (Beyotime Biotech, Shanghai, China) electrophoresis (SDS-PAGE) and transferred to polyvinylidene difluoride (PVDF) membrane (Beyotime Biotech, Shanghai, China) at a constant voltage of $80 \mathrm{~V}$. After being blocked with a rapid blocking buffer for 10-15 minutes, and the membrane was incubated at $4{ }^{\circ} \mathrm{C}$ in an ice room overnight with primary antibodies against TRPA1 (1:1,000; ACC-037, Alomeno Labs, Israel) and $\beta$-actin (1:500; Wuhan Boster Biological Technology, China). On the following day, the membrane was incubated with goat anti-rabbit IgG (1:5,000; Thermo Fisher) at $37{ }^{\circ} \mathrm{C}$ for 1 hour. After washing, the PVDF membrane was developed and photographed using enhanced chemiluminescence (ECL) reagent (Millipore, America). The gray value of the target band was analyzed using Vilber Lourmat Fusion FX7 Imaging Analyzer (Marne-la-Vallée, France). The relative protein content was shown as the ratio of the gray value of the target band to the gray value of the internal control band for semi-quantitative analysis.

\section{Quantitative reverse transcription PCR}

A small tissue block about $5-\mathrm{mm}^{3}$ in size was cut off from the preserved skin tissues, and $1 \mathrm{ml}$ of Invitrogen ${ }^{\mathrm{TM}}$ TRIzol $^{\circledR}$ reagent $(50-100 \mathrm{mg} / \mathrm{mL}$; Thermo Fisher, America) was added for extracting total RNA. Then the skin tissues were ground into homogenate using an electric homogenizer. Chloroform was then added for separation. After shaking and blending, the mixture was put on ice for 15 minutes and then centrifuged at $12,000 \mathrm{rpm}$ at $4{ }^{\circ} \mathrm{C}$ for 15 minutes. Subsequently, the upper aqueous phase of the centrifuge tube was removed, followed by adding isopropanol, well mixing, standing for 5-10 minutes, and centrifugation at $12,000 \mathrm{rpm}$ for 10 minutes. After discarding the supernatant, the precipitate was mixed with $75 \%$ ethanol by gently shaking in the centrifuge tube, followed by suspension and precipitation, and centrifugation at $8,000 \mathrm{rpm}$ at $4{ }^{\circ} \mathrm{C}$ for 5 minutes. Then the tube received air dry on ice for 5-10 minutes after carefully discarding the supernatant, and then $20 \mu \mathrm{L}$ RNase-free water was added into the tube to dissolve the precipitate. For each test, $2 \mu \mathrm{L}$ RNA sample was taken for determining concentration and purity, and the rest was stored in a refrigerator at $-80^{\circ} \mathrm{C}$ for later use.

Then RNA was reversely transcribed into cDNA using the PrimeScript ${ }^{\mathrm{TM}}$ RT reagent kit (Takara Bio, Japan). The reverse transcription system included $2.0 \mu \mathrm{L} 5 \times$ PrimeScript Buffer (for real-time), $0.5 \mu \mathrm{L}$ PrimeScript RT Enzyme Mix I, $0.5 \mu \mathrm{L}$ Oligo dT Primer $(50 \mu \mathrm{M}), 2 \mu \mathrm{L}$ random, 6 mers $(100 \mu \mathrm{M})$, $1,000 \mathrm{ng}$ Total RNA, and a certain amount of RNase Free $\mathrm{dH}_{2} \mathrm{O}$ to reach a reaction volume of $10 \mu \mathrm{L}$. The reaction mixture was incubated under the following conditions: $37^{\circ} \mathrm{C}$ for 15 minutes, $85^{\circ} \mathrm{C}$ for 5 seconds, and $4^{\circ} \mathrm{C}$ for 5 minutes.

The reaction system for $\mathrm{cDNA}$ amplification included 12.5 $\mu \mathrm{L} \mathrm{SYBR}^{\circledR}$ Premix Ex Taq ${ }^{\mathrm{TM}}$ II (Takara Bio, Japan), 
Table 1 Primer sequences for quantitative reverse transcription PCR

\begin{tabular}{lcc}
\hline Gene & Forward primer & Reverse primer \\
\hline TRPA1 & ACCTGTCAGAGGCTCCTACAAGAC & TGCTGCCAGATGGAGAGGAGTC \\
IL-6 & CACTGGTCTTTTGAGTTTGAG & GGACTTTTGTACTCATCTGCAC \\
IL-13 & CATGTCCGAGACACCAAAATC & CCCTCGCGAAAAAGTTTCTTTA \\
ET-1 & TAGCCAAAAAGACAAGAAGTGC & TTCTTCCTCTCACTAACTGCTG \\
TSLP & GACCAAAAGTACCGAGTTCAAC \\
Substance $P$ & TTGAAGGTTAGGCTCTGGATTT \\
GAPDH & GCAGAAGAAATAGGAGCCAATG & CATAAAGAGCCTTTAACAGGGC \\
\hline
\end{tabular}

TRPA1, transient receptor potential ankyrin 1; IL-6, interleukin-6; IL-13, interleukin-13; ET-1, endothelin-1; TSLP, thymic stromal lymphopoietin; GAPDH, glyceraldehyde 3-phosphate dehydrogenase.

$1 \mu \mathrm{L}$ forward primer $(10 \mu \mathrm{M}), 1 \mu \mathrm{L}$ reverse primer $(10 \mu \mathrm{M}), 2 \mu \mathrm{L}$ cDNA template solution $(<100 \mathrm{ng})$, and 8.5 $\mathrm{LL}$ DEPC-treated water. The reaction conditions were as follows: pre-denaturation at $95{ }^{\circ} \mathrm{C}$ for 30 seconds, followed by 39 cycles of denaturation at $95{ }^{\circ} \mathrm{C}$ for 5 seconds and annealing at $60{ }^{\circ} \mathrm{C}$ for 30 seconds, and lastly an extension at $65^{\circ} \mathrm{C}$ for 30 seconds. The relative mRNA expression level of target genes, including TRPA1, interleukin (IL)-6, IL-13, endothelin-1 (ET-1), thymic stromal lymphopoietin (TSLP) and substance $\mathrm{P}$ in relative to GAPDH (glyceraldehyde 3-phosphate dehydrogenase) was calculated by the $2^{-\Delta \Lambda \mathrm{Ct}}$ method. The operations of qRT-PCR were performed using the Bio-Rad $\mathrm{iQ}^{\mathrm{TM}} 5$ Real-Time PCR Detection System (Bio-Rad, CA, USA). Primers used in this study were obtained from Sangon Biotech Co., Ltd., Shanghai, China. The primer sequences for PCR are shown in Table 1.

\section{Statistical analysis}

All the data were analyzed using the SPSS 24.0 software package (SPPS Inc., Chicago, USA). The measurement data that obeyed the normal distribution were expressed as the mean \pm standard deviation, and their comparisons were performed using a $t$-test. The data that did not obey the normal distribution was expressed by the median (interquartile range), and their comparisons were performed using the ranksum test. $P$ value $<0.05$ was considered statistically significant.

\section{Results}

TRPA1 expression in LSC was significantly decreased in western blot assay

The TRPA1 antibody recognized an expected band
$(128 \mathrm{kDa})$ in the western blot assay, as shown in Figure $1 \mathrm{~A}$. Figure $1 B$ showed that the TRPA1 expression in LSC group $[1.08(0.32,1.44)]$ was significantly lower than compared with the control group $[1.25(0.62,2.10)](\mathrm{P}<0.01)$.

\section{Immunohistochemical analysis showed a more significant decrease in TRPA1 expression in the epidermis of LSC}

The expression of TRPA1 in LSC $(0.14 \pm 0.01)$ was significantly decreased as compared with normal skin $(0.19 \pm 0.02)(\mathrm{P}<0.05)$, as shown in Figure $2 A$. Figure $2 B$ shows there was no statistical difference between TRPA1 expression in the epidermis and that in the dermis in the control group. However, the expression of TRPA1 in the epidermis was significantly lower than that in the dermis in the LSC group $(\mathrm{P}<0.05)$, indicating that the expression of the TRPA1 protein receptor was more obvious downregulated in the epidermis in LSC. As shown in Figure 2C, all the layers of the skin involving keratinocytes, vascular endothelial cells, and fibers presented TRPA1immunopositive expression, and higher expression was found in the basal layer and around the vessels of the dermis.

\section{qRT-PCR showed no statistical difference between the LSC group and Control group in TRPA1 mRNA expression}

As shown in Figure $3 A$, the results showed that the expression of TRPA1 mRNA in control group patients was 1.45 times higher than that in LSC, but with no statistical difference $(\mathrm{P}>0.05)$. Moreover, Figure $3 B$ shows that no statistically significant differences were found between the LSC group and the control group in the relative mRNA 
A

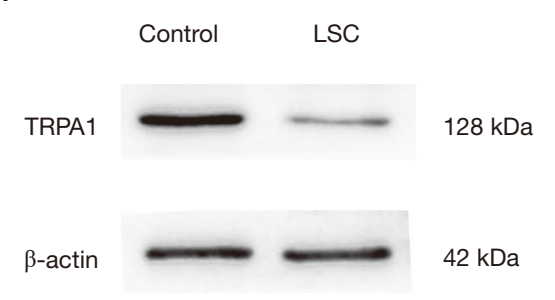

B

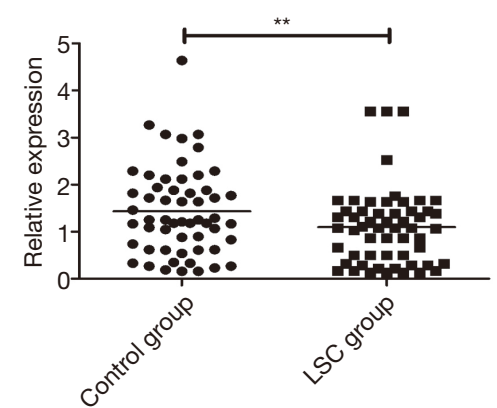

Figure 1 Protein expression of TRPA1 in the LSC group and control group. (A) Western blot results for TRPA1 expression in skin tissues of healthy controls and patients with LSC; (B) the TRPA1 expression in LSC skin tissues was significantly decreased as compared with the control group. ${ }^{* *}, \mathrm{P}<0.01$. TRPA1, transient receptor potential ankyrin 1 ; LSC, lichen simplex chronicus.

A

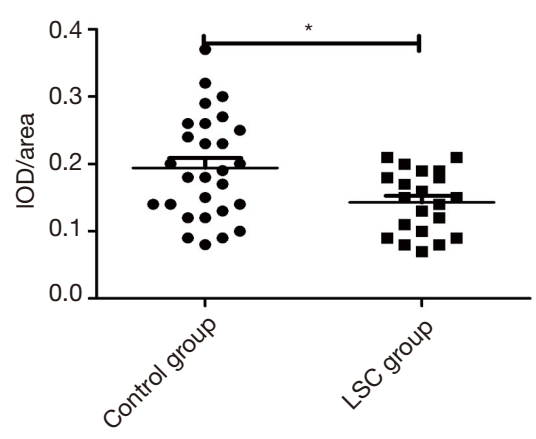

C

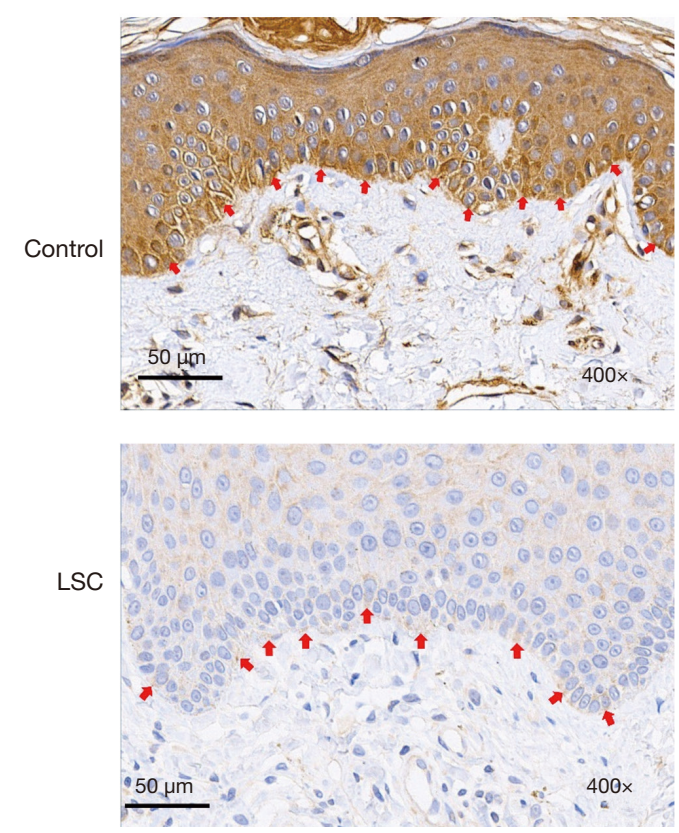

B

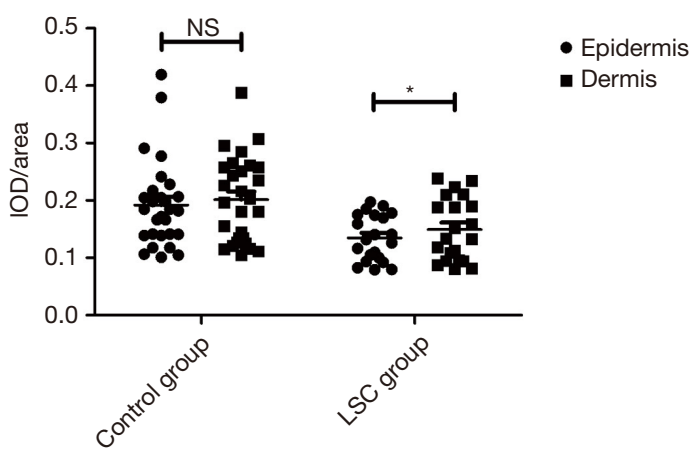

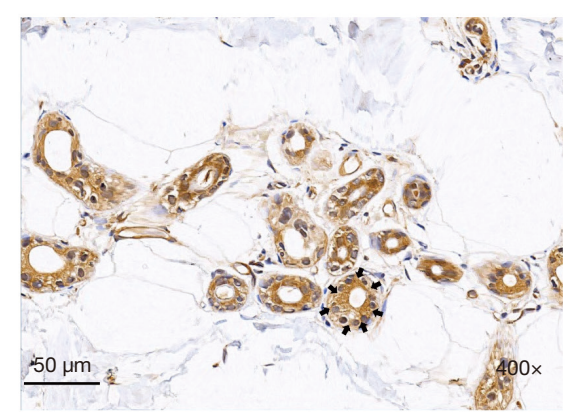

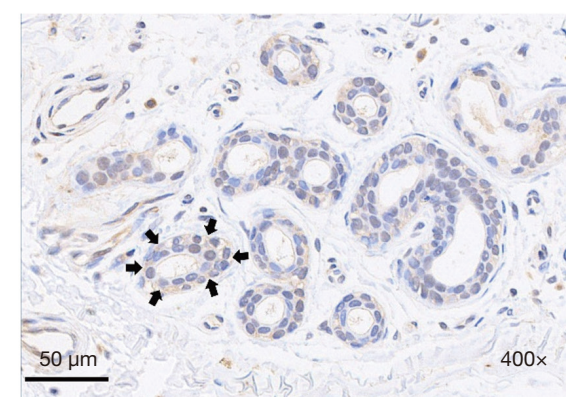

Figure 2 Expression of TRPA1 in the LSC group and control group by Immunohistochemical analysis. (A) The expression of TRPA1 in skin tissue of LSC group and control group, ${ }^{*}, \mathrm{P}<0.05$; (B) the expression of TRPA1 in the epidermis and dermis tissue of LSC group and control group, ${ }^{*}, \mathrm{P}<0.05$; (C) expression of TRPA1 in skin tissue of normal control group and LSC patients; the red arrows point to the basal layer, and the black arrows point to the blood vessels by immunohistochemical study with TRPA1. TRPA1, transient receptor potential ankyrin 1; LSC, lichen simplex chronicus. 
A

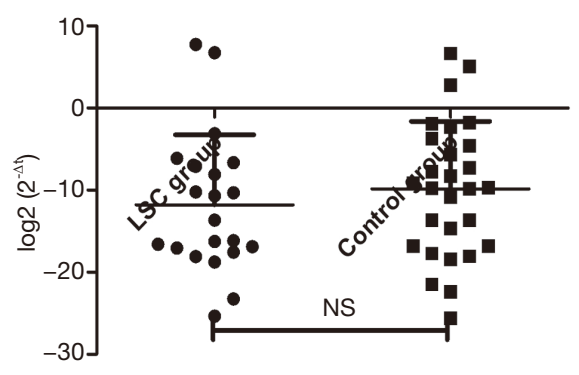

B

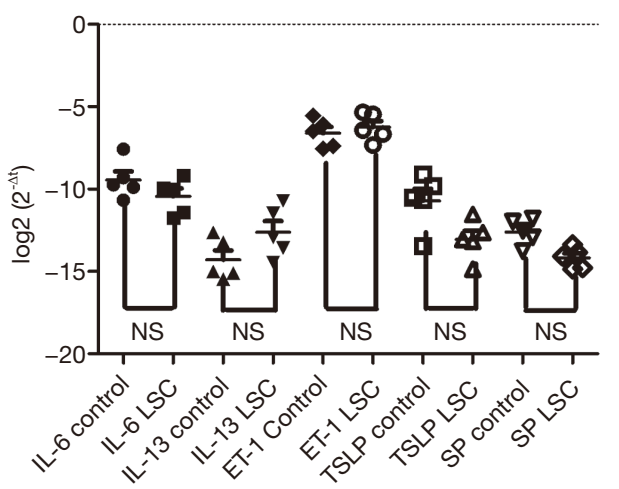

Figure 3 TRPA1 and inflammatory mediators in the skin tissue specimens mRNA expression in the LSC group and control group. (A) TRPA1 mRNA expression in the LSC group and control group; (B) inflammatory mediators in skin tissue specimens mRNA expression in the LSC group and control group. TRPA1, transient receptor potential ankyrin 1; LSC, lichen simplex chronicus.

expressions of IL-6, IL-13, ET-1, TSLP, and substance P.

\section{Discussion}

People burdened with LSC report frequent pruritus, followed by obsessive-compulsive scratching or rubbing of the corresponding body region. Recent studies have shown TRPA1 is an ion channel activated and/or regulated by various signaling pathways, and play an essential role in chronic pruritus as it severs as a downstream channel for the pathways of multiple histamine-independent pruritus induced by ET-1, ROS, TSLP, IL-31, IL-13, LTB 4, and bile acid in itch transmission $(3,10,15)$.

Earlier research on the relationship between TRPA1 and itching sensation mostly focused on the sensory nerves of mice. The expression of TRPA1 in sensory nerve fibers in the dermis and dorsal root ganglia was significantly enhanced in pruritus, and the response of sensory neurons of TRPA1 knock-out mice to itch mediators was significantly weakened $(3,4,11,12,16)$, indicating that the activation of TRPA1 and its increase in expression in neuronal cells acts as a pivotal role in itch transmission. Besides, some researchers believe pruritus is not only related to neural networks in the skin but also involved with nonneural cells like mast cells and keratinocytes (17). Previous studies have confirmed the TRPA1 channel is expressed in keratinocytes, melanocytes, fibroblasts, and other nonneuronal cells and is mainly distributed in the basal layer, dermis, and hair follicle epithelial cells (18-20).

In this study, we aimed to find out whether TRPA1 expression is abnormal in skin lesions of a dermatosis accompanied by pruritus, and we chose LSC patients as the research subjects. The changes in TRPA1 expression in LSC and normal skin tissues were compared. Immunohistochemical analysis showed that the expression of TRPA1 in LSC skin tissues was significantly lower than that in normal skin tissues, which is consistent with the results in western blot analysis. We also detected the mRNA expression of inflammatory mediators, including IL-6, IL-13, ET-1, TSLP, and substance P, and found no significant difference between the two kinds of tissues above. The literature review pointed out that pathological changes attributable to chronic inflammation in LSC skin tissues are related to repeated immune responses, and Langerhans cells and $\mathrm{CD}^{+} \mathrm{T}$ cells act as significant roles in the initiation of the immune responses. Activated Langerhans cells owing to some factors like mental pressure could cause local immune responses and damage the tissues, followed by local pruritus (21).

Additionally, external scratching, rubbing, skin dryness, and other stimuli could enhance the immune responses, leading to apparent inflammatory infiltration, thickening of the epidermis, and local fibrosis; $\mathrm{CD}^{+} \mathrm{T}$ cells can promote not only keratinocyte proliferation but also extend the inflammatory damage to the skin, a crucial factor in regulating immunopathologic processes (22). In view of the important role of $\mathrm{CD}^{+} \mathrm{T}$ cells in the pathogenesis of LSC, TRPA1 may affect local skin immunity by influencing $\mathrm{CD} 4+\mathrm{T}$ cells. It has been confirmed that pro-inflammatory response can be induced by neural TRPA1 activation, but there is still new evidence that proves the protective effect of TRPA1. The deletion of the TRPA1 gene can enhance inflammatory response in various animal colitis models 
$(23,24)$, and it exerts the anti-inflammatory effect through profound and continuous desensitization of TRPA1 channels (25). Some studies have also found the TRPA1 gene presents expression in $\mathrm{CD}^{+} \mathrm{T}$ cells, and it inhibits the activation of $\mathrm{CD}^{+} \mathrm{T}$ cells by inhibiting the activity of TRPV1 channels in $\mathrm{CD}^{+} \mathrm{T}$ cells, thus inhibiting $\mathrm{T}$ cellmediated colitis (24). The imiquimod-induced psoriasislike dermatitis in TRPA1 knock-out mice treated with TRPA1 antagonist (A967079) was significantly aggravated, indicating that TRPA1 receptors expressed in neurons or non-neurons have protective effects on psoriasis-like dermatitis (26). These results suggest that anti-inflammatory activity provoked by non-neuronal activation of TRPA1 is of more benefit as compared with its pro-inflammatory effect on sensory nerves (26). Therefore TRPA1 may play an anti-inflammatory role in LSC. We could infer based above findings that low expression of TRPA1 in LSC skin tissues may weaken the inhibition of TRPV1 in $\mathrm{CD}^{+} \mathrm{T}$ cells, and activate $\mathrm{CD}^{+} \mathrm{T}$ cells, followed by aggravated inflammation, but the detailed mechanism requires further research. We may also infer the roles TRPA1 plays vary in different non-neuronal cells and diseases. For example, mast cells in patients with atopic dermatitis aggravate the inflammation through TRPA1 (12); and TRPA1 works as a protective role in colitis by inhibiting $\mathrm{CD}^{+} \mathrm{T}$ cells (24).

It has been reported that TRPA1 expression is elevated in skin tissues of some dermatosis, including atopic dermatitis and lichen planus. For example, Oh et al. found TRPA1 was highly expressed in dermal cells, afferent neurons and keratinocytes of 3 patients with atopic dermatitis, and its expression in mast cells also existed in 4 normal people (12). RNA sequencing resulted in a study including skin tissue specimens from 25 patients with atopic dermatitis and 25 healthy controls, showed that TRPA1 mRNA was increased in skin tissue from the patients, while there was no significant difference in numbers of TRPA1 positive cutaneous nerve fibers between the two groups (27). Yang et al. also confirmed the increase in TRPA1 mRNA expression in the scar tissues from 33 burn scar patients with pruritus using quantitative PCR, but the immunohistochemical analysis showed no statistical difference between the patients and 18 burn scar patients without pruritus (28). Kun et al. confirmed the increase in TRPA1 expression in the lesions from 9 controls and 43 patients with oral lichen planus through immunofluorescence assay and quantitative PCR (29). The above results showed that TRPA1 presents higher expression in non-neuronal cells in diseases associated with pruritus, including atopic dermatitis, and it plays a role in promoting inflammation or conducting itch sensation. These results are contrary to what we found in the study, but they reveal that TRPA1 plays different roles in different diseases and cells, and its detailed underlying mechanism is worthy of further in-depth study with discussion.

In summary, we provide evidence for TRPA1 downregulation in LSC skin tissues, suggesting that chronic pruritus may be related to ion channels in skin tissues, but its specific mechanism needs further study.

\section{Acknowledgments}

Funding: cstc2018jcyjA0740 from the Chongqing Science and Technology Bureau, China. cx2018148 from the Health Select Committee, China.

\section{Footnote}

Reporting Checklist: The authors have completed the MDAR reporting checklist. Available at http://dx.doi.org/10.21037/ apm-20-1712

Data Sharing Statement: Available at http://dx.doi. org/10.21037/apm-20-1712

Conflicts of Interest: All authors have completed the ICMJE uniform disclosure form (available at http://dx.doi. org/10.21037/apm-20-1712). The authors have no conflicts of interest to declare.

Ethical Statement: The authors are accountable for all aspects of the work in ensuring that questions related to the accuracy or integrity of any part of the work are appropriately investigated and resolved. All procedures performed in this study involving human participants were in accordance with the Declaration of Helsinki (as revised in 2013). The Ethics Committee approved the study of the First Affiliated Hospital of Chongqing Medical University. Signed written informed consent was obtained from the patients and/or guardians.

Open Access Statement: This is an Open Access article distributed in accordance with the Creative Commons Attribution-NonCommercial-NoDerivs 4.0 International License (CC BY-NC-ND 4.0), which permits the noncommercial replication and distribution of the article with the strict proviso that no changes or edits are made and the original work is properly cited (including links to both the 
formal publication through the relevant DOI and the license). See: https://creativecommons.org/licenses/by-nc-nd/4.0/.

\section{References}

1. Ramsey IS, Delling M, Clapham DE. An introduction to TRP channels. Annu Rev Physiol 2006;68:619-47.

2. Story GM, Peier AM, Reeve AJ, et al. ANKTM1, a TRPlike channel expressed in nociceptive neurons, is activated by cold temperatures. Cell 2003;112:819-29.

3. Wilson SR, Gerhold KA, Bifolck-Fisher A, et al. TRPA1 is required for histamine-independent, Mas-related G protein-coupled receptor-mediated itch. Nat Neurosci 2011;14:595-602.

4. Roberson DP, Gudes S, Sprague JM, et al. Activitydependent silencing reveals functionally distinct itchgenerating sensory neurons. Nat Neurosci 2013;16:910-8.

5. Liu Q, Weng HJ, Patel KN, et al. The distinct roles of two GPCRs, MrgprC11 and PAR2, in itch and hyperalgesia. Sci Signal 2011;4:ra45.

6. Cevikbas F, Wang X, Akiyama T, et al. A sensory neuronexpressed IL-31 receptor mediates T helper celldependent itch: Involvement of TRPV1 and TRPA1. J Allergy Clin Immunol 2014;133:448-60.

7. Liu T, Ji RR. Oxidative stress induces itch via activation of transient receptor potential subtype ankyrin 1 in mice. Neurosci Bull 2012;28:145-54.

8. Liu Q, Tang Z, Surdenikova L, et al. Sensory neuronspecific GPCR Mrgprs are itch receptors mediating chloroquine-induced pruritus. Cell 2009;139:1353-65.

9. Zhang X. Targeting TRP ion channels for itch relief. Naunyn Schmiedebergs Arch Pharmacol 2015;388:389-99.

10. Wilson SR, Nelson AM, Batia L, et al. The ion channel TRPA1 is required for chronic itch. J Neurosci 2013;33:9283-94.

11. Liu B, Escalera J, Balakrishna S, et al. TRPA1 controls inflammation and pruritogen responses in allergic contact dermatitis. Faseb j 2013;27:3549-63.

12. Oh MH, Oh SY, Lu J, et al. TRPA1-dependent pruritus in IL-13-induced chronic atopic dermatitis. J Immunol 2013;191:5371-82.

13. Redelfs L, Fischer J, Weber C, et al. The serine protease inhibitor of Kazal-type 9 (SPINK9) is expressed in lichen simplex chronicus, actinic keratosis and squamous cell carcinoma. Arch Dermatol Res 2016;308:133-7.

14. Edwards SK, Bates CM, Lewis F, et al. 2014 UK national guideline on the management of vulval conditions. Int $\mathrm{J}$
STD AIDS 2015;26:611-24.

15. Luo J, Feng J, Liu S, et al. Molecular and cellular mechanisms that initiate pain and itch. Cell Mol Life Sci 2015;72:3201-23.

16. Kittaka H, Tominaga $M$. The molecular and cellular mechanisms of itch and the involvement of TRP channels in the peripheral sensory nervous system and skin. Allergol Int 2017;66:22-30.

17. Bandell M, Story GM, Hwang SW, et al. Noxious cold ion channel TRPA1 is activated by pungent compounds and bradykinin. Neuron 2004;41:849-57.

18. Atoyan R, Shander D, Botchkareva NV. Non-neuronal expression of transient receptor potential type A1 (TRPA1) in human skin. J Invest Dermatol 2009;129:2312-5.

19. Ständer S, Raap U, Weisshaar E, et al. Pathogenesis of pruritus. J Dtsch Dermatol Ges 2011;9:456-63.

20. Gouin O, L'Herondelle K, Lebonvallet N, et al. TRPV1 and TRPA1 in cutaneous neurogenic and chronic inflammation: pro-inflammatory response induced by their activation and their sensitization. Protein Cell 2017;8:644-61.

21. Feng X, Wang B, Hu Y, et al. The distribution of Langerhans cells and the expression of CD40 in the tissues of neurodermatitis with its underlying significance. Current Immunololgy 2006;26:373-6.

22. Jiang SM, Wu YH, Li QL, et al. Research Advances on Etiology and Pathogenesis of Neurodermatitis. Hunan Journal of Traditional Chinese Medicine 2017;6:205-7.

23. Kun J, Szitter I, Kemény A, et al. Upregulation of the transient receptor potential ankyrin 1 ion channel in the inflamed human and mouse colon and its protective roles. PLoS One 2014;9:e108164.

24. Bertin S, Aoki-Nonaka Y, Lee J, et al. The TRPA1 ion channel is expressed in CD4+ T cells and restrains T-cellmediated colitis through inhibition of TRPV1. Gut 2017;66:1584-96.

25. Kistner K, Siklosi N, Babes A, et al. Systemic desensitization through TRPA1 channels by capsazepine and mustard oil - a novel strategy against inflammation and pain. Sci Rep 2016;6:28621.

26. Kemény Á, Kodji X, Horváth S, et al. TRPA1 Acts in a Protective Manner in Imiquimod-Induced Psoriasiform Dermatitis in Mice. J Invest Dermatol 2018;138:1774-84.

27. Nattkemper LA, Tey HL, Valdes-Rodriguez R, et al. The Genetics of Chronic Itch: Gene Expression in the Skin of Patients with Atopic Dermatitis and Psoriasis with Severe Itch. J Invest Dermatol 2018;138:1311-7.

28. Yang YS, Cho SI, Choi MG, et al. Increased expression 
of three types of transient receptor potential channels (TRPA1, TRPV4 and TRPV3) in burn scars with postburn pruritus. Acta Derm Venereol 2015;95:20-4.

29. Kun J, Perkecz A, Knie L, et al. TRPA1 receptor is

Cite this article as: Qiu Y, Tang N, Zhang W, Xiong JX, $\mathrm{Hu}$ L, Cai T. Down-regulated expression of transient receptor potential ankyrin 1 in lichen simplex chronicus. Ann Palliat Med 2020;9(6):3757-3765. doi: 10.21037/apm-20-1712 upregulated in human oral lichen planus. Oral Dis 2017;23:189-98.

(English Language Editor: J. Chapnick) 